\title{
Population dynamics of cod Gadus morhua in the North Sea region: biological density-dependent and climatic density-independent effects
}

\author{
Qingxian Chen ${ }^{1}$, Kung-Sik Chan ${ }^{2}$, Kyrre Lekve $^{3}$, Else Torstensen ${ }^{4}$, Jakob Gjøsæeter ${ }^{4}$, \\ Geir Ottersen $^{5,6}$, Nils Chr. Stenseth ${ }^{3,4, *}$ \\ ${ }^{1}$ New York State Office of Mental Health, 44 Holland Avenue, Albany, New York 12229, USA \\ ${ }^{2}$ Department of Statistics and Actuarial Science, University of Iowa, Iowa City, Iowa 52242, USA \\ ${ }^{3}$ Centre for Ecological and Evolutionary Synthesis (CEES), Department of Biology, University of Oslo, PO Box 1050 Blindern, \\ 0316 Oslo, Norway \\ ${ }^{4}$ Institute of Marine Research, Flødevigen Marine Research Station, 4817 His, Norway \\ ${ }^{5}$ Institute of Marine Research, PO Box 1870 Nordnes, 5817 Bergen, Norway
}

${ }^{6}$ Present address: Centre for Ecological and Evolutionary Synthesis (CEES), Department of Biology, University of Oslo, PO Box 1050 Blindern, 0316 Oslo, Norway

\begin{abstract}
Through the statistical modeling of monitoring data, we assess the ecological interlinkages between cod Gadus morhua L. in the North Sea, Skagerrak and Kattegat - regions which typically have been considered separate management units. The model includes both within-population density dependence (within and between age classes), as well as density-dependent effects of migration between the North Sea, Skagerrak and Kattegat. Further, the model incorporates the effects of environmental features (such as temperature and the North Atlantic Oscillation). The obtained results are discussed, both with reference to general ecological principles as well as with respect to management implication. Altogether our analysis suggests a unified management regime for the entire region including the North Sea, the open Skagerrak and Kattegat.
\end{abstract}

KEY WORDS: GAM · NAO · North Sea-Skagerrak-Kattegat system • Time-series modeling • Transport effect Resale or republication not permitted without written consent of the publisher

\section{INTRODUCTION}

\section{Cod management}

Cod Gadus morhua L. is one of the major fish resources in the North Atlantic, and its fisheries may be traced back to very early days (see Kurlansky 1997). Cod are widely distributed over the shelf waters of the North Atlantic, across an extensive range of latitudes and environmental conditions. They have been heavily exploited over the last decades, leading to a greatly reduced stock size.

In the northeast Atlantic, cod is assessed and managed within units established through the ICES (the International Council for the Exploration of the Sea; see Fig. 1). There are, however, close interlinkages between these management units, both ecologically (Garrod 1977; see also Cardinale \& Svedäng 2004) and genetically (Nielsen et al. 2001, 2003, Knutsen et al. 2003, 2004). However, such interlinkages have generally not been quantified, particularly not within a population dynamic setting; we attempt this in the present paper. Specifically, in this paper we report the results emerging from statistical modeling of survey data (see, e.g., Stenseth et al. 1999) on cod in the North Sea and the neighboring Skagerrak and Kattegat regions (Fig. 1). Through such statistical modeling, we have been able to improve understanding of the interlinked population dynamics of cod in these waters. Our focus here is on the deduction of intrinsic processes (such as 


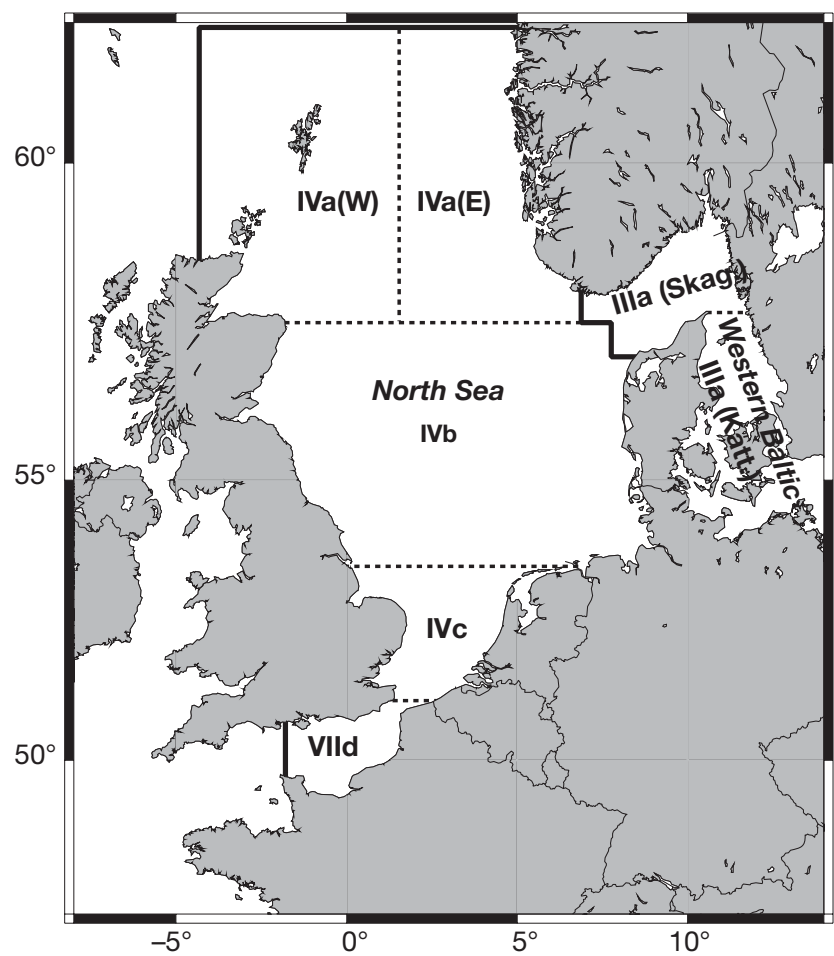

Fig. 1. The study region with sectors as defined by ICES. The North Sea stock corresponds to Sector IVb, the Skagerrak stock corresponds to Sector IIIa/ Skagerrak and the Kattegat stock corresponds to Sector IIIa/western Baltic (from ICES Harmful Algae Working Group Report 2004)

density dependence within and between cohorts) and extrinsic processes (such as climate dependence). We apply a time-series approach to deduce the underlying forms of dynamics and interactions of the populations. We analyze data on cod Gadus morhua L. from the International Bottom Trawl Survey (IBTS) monitoring surveys coordinated by the ICES, together with environmental data, in order to arrive at a joint model for the North Sea, Skagerrak and Kattegat populations. Using this approach we are able to demonstrate the effect of transport between the areas, and show that almost identical models can be used to represent the dynamics of the cod populations in the 3 areas.

The overall perspective of our study is a general one focusing on the density-dependent and densityindependent structure of populations (see, e.g., Stenseth et al. 2002), where climate is seen as the main density-dependent factor. A key focus of our paper is the interlinkage of various sub-units of the overall population (North Sea, Kattegat and Skagerrak), where each of these sub-units may affect each other in a density-dependent manner. As a platform for our analyses, we provide in the following section a synoptic account of the Skagerrak system with its neighboring waters.

\section{The North Sea-Skagerrak-Kattegat system}

Currents in the North Sea, as in any continental shelf sea, occur in response to forcing by tides, winds, density gradients (arising from freshwater input) and pressure gradients. For most of the North Sea the dominant motion is tidal, with the next most significant motion generator being wind forcing (Howarth 2001). About $70 \%$ of the water entering the North Sea is assumed to pass through the Skagerrak before leaving for the North Sea again (Danielssen et al. 1996). The general circulation pattern in the Skagerrak is counterclockwise. After passing by the northern tip of Denmark, the highly saline North Atlantic water (entering from the North Sea) is mixed with low-saline water coming from the Kattegat (originating in the Baltic Sea). This mixed water mass is termed the 'Norwegian Coastal Current' (NCC: Danielssen et al. 1997), and obtains an increasing salinity content as it flows along the Norwegian Skagerrak coast before returning to the North Sea (see Fig. 1). It should be noted that the variability of currents is extensive (e.g. the seasonal variation and variability in stratification due to salinity differences), and is influenced by atmospheric variability as well as river run-off in the German Bight (Røed \& Fossum 2004). Observations and modeling results documented by Ottersen et al. (2003) indicate for instance that the prevailing westward flowing current along the Norwegian Skagerrak coast may reverse and flow eastwards.

There are several local populations of cod in the study area, some of which are assessed as separate stocks. Since 1996, the cod populations in the Skagerrak, the North Sea and the eastern Channel have been assessed as 1 unit (ICES 2002b), but managed by separable TACs (total allowable catch). Prior to 1996 cod in these areas were assessed and managed as separate stocks. Cod in the Kattegat is considered a separate stock by the Baltic Sea Working Group (ICES 2002a). Nevertheless, the actual population differentiation among these stocks is still largely unknown (but see Nielsen et al. 2001, Knutsen et al. 2003). In addition there are cod in many fjords, which - judged by results of tagging experiments (e.g. Løversen 1946, Danielssen \& Gjøsæter 1994) — constitute semi-isolated populations. In the present paper we refer to the cod in the open Skagerrak, not to the coastal and fjord populations.

Cod spawning locations are widely distributed throughout the North Sea (Brander 1994, ICES 1994). Following Knutsen et al. (2004) and N. C. Stenseth et al. (unpubl. data) we assume that North Sea larvae may be transported from spawning grounds in the North Sea into the Skagerrak where they mix with natively produced larvae (see also Munk et al. 1995, 1999, Cardinale \& Svedäng 2004). 
The overall purpose of this study is to develop coupled statistical models of the dynamics of the 3 areas - the North Sea, the Skagerrak and the Kattegat-explicitly including the effect of potential transportation of spawning products and of migration of mature cod between the areas.

\section{MATERIALS AND METHODS}

Cod abundance. The data used in this study are based on the ICES IBTS (International Bottom Trawl Survey) monitoring surveys, which were conducted by several countries in the North Sea region during the first quarter of each year from 1965 to 2002; these surveys were coordinated by ICES and based upon direct observation of catch per unit effort (CPUE) (see Anon. 2004). More recent surveys were also conducted in other quarters, but for uniformity we focus here on data from the first quarters. These surveys cover the open ocean; cod in coastal waters and in fjords are not included.

The survey area in the North Atlantic has been classified into smaller statistical rectangles. The data consist of CPUE of cod from Age 1 to Age 6+ in each rectangle. The annual abundance estimates for each age class in each year in the North Sea, Skagerrak and Kattegat were obtained by averaging the CPUE data over the rectangles in each of these 3 regions, with the rectangle areas as weights. For Age Group 6+ in the Skagerrak, the weighted abundance estimates for 1979 and 1992 were 0 ; in our analysis they were, however, set to the observed minimum abundance of that age group, in order to facilitate the logarithmic transformation in the statistical analysis.

Spawning biomass. Assuming that essentially none of Age Group 2 cod mature, we estimated the spawning biomass $S S B_{t}$ as the sum of abundance times the average weight times the mature percent over each age group for each year, according to the following formula: $S S B_{t}=\sum_{j=3}^{6+} P_{j} N_{t, j} W_{t, j}$, where $P_{j}$ is the mature proportion of Age Group $j \operatorname{cod}\left(N_{t, j}\right)$ and $W_{t, j}$ is the mean weight for Class $j$ in Year $t$. The mature proportions and the mean weight are taken from a published ICES report (ICES 2001; S-3-Cod347d.pdf downloaded from www.ices.dk/reports/acfm/2001/wgnssk/). Specifically, $P_{j}$ are set as the proportion of mature cod by age group for the whole area (North Sea, Skagerrak and Kattegat) combined (see p. 63 of ICES 2001). The mean weights are set as mean weights at age in the stocks from 1963 to 2000 (p. 65 of ICES 2001). It is furthermore assumed that the catchability of these groups was comparable over the study period, so that the spawning biomasses may be esti- mated from the abundance estimates, up to a multiplicative constant.

Temperature. Sea temperature data from 1970 to 2001 were downloaded from the ICES oceanographic database (www.ices.dk/ocean). The temperature for each region was then obtained by averaging the data first over each month and then over each year. For younger cod, we used the average upper 5 to $10 \mathrm{~m}$ water temperature. For older cod we used the average upper 5 to $50 \mathrm{~m}$ water temperature. The upper $5 \mathrm{~m}$ water temperature data were excluded to avoid aliasing problems caused by rapid variation in surface water temperature due to solar heating. In addition, for Age Group 1 cod, we used the previous year's temperature in March, as this represents the peak of the spawning season (North Sea: Brander 1994); for all other age groups, we used the previous year's average temperature.

Climate data - the North Atlantic Oscillation. The North Atlantic Oscillation (NAO) is a large-scale fluctuation in atmospheric mass between the sub-tropical North Atlantic region (centered around the Azores) and the sub-polar North Atlantic region (centered around Iceland). As an index for winter climate, we used the winter NAO index of Hurrell (1995; see also Stenseth et al. 2003), which is based on the difference of normalized sea level pressures between Lisbon, Portugal, and Stykkisholmur/Reykjavik, Iceland, for the months December through March (www.cgd.ucar. edu/ jhurrelll/nao.html\#winter). The NAO has been de-trended by subtracting from the raw indices a smooth trend function fitted from a generalized additive model (GAM), with NAO as response and year as a covariate with $5 \mathrm{df}$ (see next subsection). We used the de-trended NAO for our model fitting. We have focused on de-trended NAO values so as to avoid trends in the NAO leading us to find spurious effects due to the trend itself (as opposed to the fluctuation in the NAO, which is after all the key focus of this climate index). We have also repeated the analysis using raw NAO data, and the model fits are similar to the results reported below.

The population dynamic models and the statistical modeling. To account for the inter-relationship and possibly common population dynamic structure of the North Sea, the Skagerrak and the Kattegat populations, we modeled the 3 systems jointly. To facilitate reading and interpretation of the model structure, we have provided an overview of the terms used in the model in Table 1.

Let $t$ denote time (i.e. years from 1965 to 2002) and $j$ denote the age of cod. Let $X_{t, j}^{\mathrm{N}}, X_{t, j}^{\mathrm{S}}$ and $X_{t, j}^{\mathrm{K}}$ denote the abundance of cod in Year $t$ of Age Group $j$ for the North Sea area, the Skagerrak area and the Kattegat area, respectively. The lowercase variables (e.g. $x_{t, j}^{\mathrm{N}}$ ) 
Table 1. Terms included in the model

\begin{tabular}{|c|c|}
\hline Term & Interpretation \\
\hline$X_{t, j}^{\mathrm{N}}, X_{t, j}^{\mathrm{S}}$ and $X_{t, j}^{\mathrm{K}}$ & $\begin{array}{l}\text { Sampled abundance of cod in Year } t \text { of Age Group } j \text { for the North Sea area }(\mathrm{N}) \text {, the Skagerrak } \\
\text { area (S) and the Kattegat area }(\mathrm{K}) \text {, respectively. The index } t \text { signifies the year, and the index } j \text { the } \\
\text { age class. (Lowercase } x \text { represents log-transformed abundances) }\end{array}$ \\
\hline$S S B_{t}^{\mathrm{N}}, S S B_{t}^{\mathrm{S}}$ and $S S B_{t}^{\mathrm{K}}$ & $\begin{array}{l}\text { The spawning biomass in Year } t \text { for the } 3 \text { areas. (Lowercase } s s b \text { represents log-transformed } \\
\text { spawning biomass) }\end{array}$ \\
\hline$T_{t}$ & Temperature at time $t$ \\
\hline$C_{t}$ & Climate condition, e.g. North Atlantic Oscillation (NAO) de-trended value in Year $t$ \\
\hline Statistical model term & Constant term \\
\hline$\varepsilon_{t, j}^{\text {Area }}$ & Noise-term for the indicated area in Time $t$ for Age Group $j$ in 'Area' \\
\hline$f .$. & $\begin{array}{l}\text { A function (linear or non-linear), indexed according to predictor variable. The indices are simpli- } \\
\text { fied (see 'The population dynamic models and the statistical modeling') }\end{array}$ \\
\hline$g .$. & $\begin{array}{l}\text { A function used when expressing density dependence of the survival rate from Age Group } j \text { to } \\
j+1 . f(x)=g(x)+\log (X) \text {, implying that } g(x)=f(x)-\log (X)\end{array}$ \\
\hline
\end{tabular}

denote the corresponding log-transformed variables $\left(X_{t, j}^{\mathrm{N}}\right)$. Let $S S B_{t}^{\mathrm{N}} S S B_{t}^{\mathrm{S}}$ and $S S B_{t}^{\mathrm{K}}$ be the spawning biomass in Year $t$ for the North Sea, Skagerrak and Kattegat, respectively (with corresponding lower case variables denoting log-transformed variables).

In the following, we study how the (log-transformed) abundance of the various groups depends on population structure and various abiotic factors (water temperature and the NAO). As these relationships need

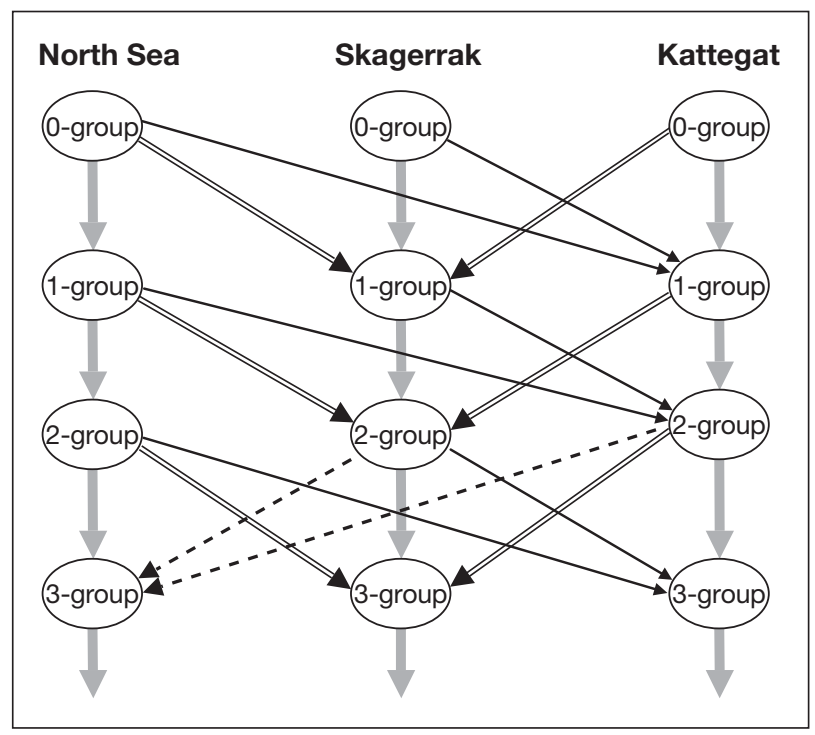

Fig. 2. Inter-age-group relationship of the cod systems of the 3 regions. Gray arrows represent density dependence; double arrows represent transportation effect to Skagerrak; single solid arrows represent transportation effect to Kattegat region; dashed arrows represent transportation effect to North Sea region. Age 4+ groups enjoy similar relationships to Age 3 groups and are hence omitted from the figure not be linear, we employ the GAM (Hastie \& Tibshirani 1990). We specify generalized additive models for each age group in the 3 systems as follows: $T$ stands for water temperature and $C$ stands for climate as incorporated through the NAO index (see Fig. 2 for a schematic diagram showing the inter-relationships of the age groups of the 3 systems).

\section{North Sea:}

Age Group 1:

$\log \left(X_{t, 1}^{\mathrm{N}}\right)=\beta_{0}+f_{s \mathrm{~N}}\left(s s b_{t-1}^{\mathrm{N}}\right)+f_{T}\left(T_{\text {march }, t-1}\right)+f_{C}\left(C_{t}\right)+\varepsilon_{t, 1}^{\mathrm{N}}(1)$

Age Group 2:

$\log \left(X_{t, 2}^{\mathrm{N}}\right)=\beta_{0}+f_{x \mathrm{~N}}\left(x_{t-1,1}^{\mathrm{N}}\right)+f_{T}\left(T_{t-1}\right)+f_{C}\left(C_{t}\right)+\varepsilon_{t, 2}^{\mathrm{N}}$

(Note that, strictly speaking, the functions $f_{T}$ appearing on the right side of Eqs. (1) \& (2) should be labeled as $f_{\mathrm{N}, 1, T}$ and $f_{\mathrm{N}, 2, T}$ as they represent possibly different functions. However, for simplicity, we retain the simpler notations; this similarly holds for other function notations.) We assume that the juvenile cod stay in the littoral zone until they reach sexual maturation at around 3 to $4 \mathrm{yr}$ of age. Thus, we need to include migrating cod in the equations from Age Group 3. The coastal cod settle in the littoral zone as juveniles, but the oceanic cod stocks do not. There is, however, an inshore migration among the 0 and 1 groups, and they stay at more shallow waters than the adults (see, e.g., Riley \& Parnell 1984).

Age Group 3:

$$
\begin{aligned}
\log \left(X_{t, 3}^{\mathrm{N}}\right)= & \beta_{0}+f_{x \mathrm{~N}}\left(x_{t-1,2}^{\mathrm{N}}\right)+f_{x \mathrm{~S}}\left(x_{t-1,2}^{\mathrm{S}}\right) \\
& +f_{x \mathrm{~K}}\left(x_{t-1.2}^{\mathrm{K}}\right)+f_{T}\left(T_{t-1}\right)+f_{C}\left(C_{t}\right)+\varepsilon_{t, 3}^{\mathrm{N}}
\end{aligned}
$$

Similar equations hold for Age Group 4 through Group 6+. 
Skagerrak: The water masses flow from the North Sea to Skagerrak and, to a lesser degree, into the Kattegat. For younger cod and larvae, we need to include a transportation effect from the North Sea. The transportation mechanism between the Skagerrak and Kattegat is less clear. In the analysis, we tentatively included a transportation effect from the Kattegat.

Age Group 1:

$$
\begin{aligned}
\log \left(X_{t, 1}^{\mathrm{S}}\right)= & \beta_{0}+f_{s \mathrm{~S}}\left(s s b_{t-1}^{\mathrm{S}}\right)+f_{s \mathrm{~N}}\left(s s b_{t-1}^{\mathrm{N}}\right)+f_{s \mathrm{~K}}\left(s s b_{t-1}^{\mathrm{K}}\right) \\
& +f_{T}\left(T_{\text {march }, t-1}\right)+f_{C}\left(C_{t}\right)+\varepsilon_{t, 1}^{\mathrm{S}}
\end{aligned}
$$

Age Group 2:

$$
\begin{aligned}
\log \left(X_{t, 2}^{\mathrm{S}}\right)= & \beta_{0}+f_{X \mathrm{~S}}\left(x_{t-1,1}^{\mathrm{S}}\right)+f_{x \mathrm{~N}}\left(X_{t-1,1}^{\mathrm{N}}\right)+f_{\mathrm{xK}}\left(x_{t-1,1}^{\mathrm{K}}\right) \\
& +f_{T}\left(T_{t-1}\right)+f_{C}\left(C_{t}\right)+\varepsilon_{t, 2}^{\mathrm{S}}
\end{aligned}
$$

Age Group 3+:

$$
\begin{aligned}
\log \left(X_{t, 3}^{\mathrm{S}}\right)= & \beta_{0}+f_{X \mathrm{~S}}\left(X_{t-1,2}^{\mathrm{S}}\right)+f_{X \mathrm{~N}}\left(x_{t-1,2}^{\mathrm{N}}\right)+f_{X K}\left(x_{t-1,2}^{\mathrm{K}}\right) \\
& +f_{T}\left(T_{t-1}\right)+f_{C}\left(C_{t}\right)+\varepsilon_{t, 3}^{\mathrm{S}}
\end{aligned}
$$

Kattegat: For the Kattegat system, the equations resemble those for the Skagerrak.

\section{Age Group 1:}

$$
\begin{aligned}
\log \left(X_{t, 1}^{\mathrm{K}}\right)= & \beta_{0}+f_{s \mathrm{~K}}\left(s s b_{t-1}^{\mathrm{K}}\right)+f_{s \mathrm{~N}}\left(s s b_{t-1}^{\mathrm{N}}\right)+f_{s \mathrm{~S}}\left(s s b_{t-1}^{\mathrm{S}}\right) \\
& +f_{T}\left(T_{\text {march }, t-1}\right)+f_{C}\left(C_{t}\right)+\varepsilon_{t, 1}^{\mathrm{K}}
\end{aligned}
$$

Age Group 2:

$$
\begin{aligned}
\log \left(X_{t, 2}^{\mathrm{K}}\right)= & \beta_{0}+f_{X \mathrm{XK}}\left(x_{t-1,1}^{\mathrm{K}}\right)+f_{X \mathrm{~N}}\left(X_{t-1,1}^{\mathrm{N}}\right)+f_{X \mathrm{~S}}\left(X_{t-1,1}^{\mathrm{S}}\right) \\
& +f_{T}\left(T_{t-1}\right)+f_{C}\left(C_{t}\right)+\varepsilon_{t, 2}^{\mathrm{K}}
\end{aligned}
$$

The equations for Groups 3, 4, 5 and 6+ are similar to that of Group 2 and hence omitted.

Density dependence. In order to avoid spurious effects of density dependence, we have modeled the abundance as a function of past abundances (as well as other covariates); thus defined, significant density dependence will then be seen whenever the slope is $<1$. When the past abundance is found to be significant, the model equation can — and will — be reexpressed so that the response variable is changed from (log-transformed) abundance into (log-transformed) survival rates from Age Group $j$ to $j+1$ by setting $f_{X}(X)=g_{X}(X)+\log (X)$ and rearranging the terms. This is done to facilitate the model interpretation. For example, for the North Sea Age Group 3, it is found that the log-transformed abundance depends significantly on the log-transformed abundance of Age Group 2; we re-express the corresponding model equation as follows:

$$
\begin{aligned}
& \log \left(X_{t, 3}^{\mathrm{N}}\right)-\log \left(X_{t-1,2}^{\mathrm{N}}\right)=\beta_{0}+g_{x \mathrm{~N}}\left(x_{t-1,2}^{\mathrm{N}}\right) \\
& \quad+f_{x \mathrm{~S}}\left(X_{t-1,2}^{\mathrm{S}}\right)+f_{x \mathrm{XK}}\left(x_{t-1,2}^{\mathrm{K}}\right)+f_{T}\left(T_{t-1}\right)+f_{W}\left(W_{t}\right)+\varepsilon_{t, 3}^{\mathrm{N}}
\end{aligned}
$$

Then, density dependence remains if and only if the function estimate of $g_{X N}$ is significantly different from the zero function (which typically will correspond to ordinary density dependence when it is $<0$ ). The stochastic errors in these models are assumed to be serially and contemporaneously uncorrelated. Finally, we note that the time plots of the data suggest that several series may have outliers. We allow for outlier effects by including dummy variables that are equal to 1 for years that may be outliers; significant outliers were thus accounted for in the final model.

The statistical model-fitting. All models were estimated by the GAM function in the mgcv library of R (http://cran.r-project.org/). Specifically, each equation was estimated by minimizing an objective function, which equals a sum consisting of the residual sum of squares and a summand for each function in the equation that is proportional to the roughness of the function. The roughness of a function is measured by the integral of the squared second derivative of the function, and the proportionality constants are known as the smoothing parameters that quantify the trade-off between the goodness of fit and the smoothness of the function estimates. GAM assumes that the responses depend additively on the covariates, but the functional response corresponding to each covariate may be linear or non-linear. Our analysis builds upon the recent work of Wood $(2000,2004)$, which allows estimation of the smoothing parameters as well as the degrees of freedom (the degree of non-linearity) of the functions from the data, based on the generalized cross validation (GCV) criterion. The function estimates can be shown to be natural cubic splines (i.e. they consist of piecewise cubic polynomials that are joined so that the overall curve has a continuous second derivative and is linear at the 2 ends; the third derivative, however, may have jump discontinuities at the locations [knots] where the cubic polynomials are pasted together). For unit degree of freedom, the spline becomes a linear function passing through the origin. In order for the model to be identifiable, each function estimate is centered (i.e. the mean of the function estimates over the data equals zero).

The final model was determined using the following procedure suggested by Wood (2001). A term in a model equation is removed if (1) the estimated degrees of freedom for the term are close to 1 , (2) the plotted confidence band for the term includes zero everywhere and (3) the GCV score drops when the term is dropped. However, a term may be dropped if Items 1 and 2 hold, even if there is a small increase in the GCV. Because of correlations between the covariates, terms are dropped one at a time, starting with the term for which the zero line is most comfortably within the confidence band. A model is considered final if none of the terms remaining in the model can be dropped. 
To check for confounding between the 2 covariates temperature and NAO, we have done the analysis both with and without NAO as 1 of the covariates. Using the above model and assuming the stochastic errors in these models to be serially and contemporaneously uncorrelated, we tested for (1) effects of density dependence (at a lag of $1 \mathrm{yr}$ ), (2) effects of transportation and/or migration, (3) effects of temperature and (4) effects of the NAO.

\section{MODELING RESULTS}

Incorporating the effect of outlying years, the results are summarized in Table 2 and Fig. 3. In particular, Table 2 indicates which effects are significant by a qualitative description of their functional form, as cross-classified by region and age group. Non-signifi- cant effects are represented as blanks in Table 2. The significant function estimates are plotted in Fig. 3. Also, the year information of the outliers and the adjusted $\mathrm{R}^{2}$ of the model fits are given there. Since excluding the NAO from the model did not change the results in any significant way (not shown), we have kept the NAO as a covariate in the model. For 4 of the age-specific equations in the 3 areas, the additivity assumption was marginally rejected (p-values between 0.025 and 0.045 ) - suggesting some interaction not incorporated in the current model structure (see the end of this section). In spite of this, we feel confident that the model captures much of the dynamic structure of the inter-lined cod populations in the North Sea, Skagerrak and Kattegat system.

Lag 1 is insignificant in all 3 regions for Age Group 1 (dependence on the standing stock biomass the previous year). None of the covariates are significant in the North

Table 2. Significant effects in the final model ( $\mathrm{S}$, Skagerrak; N, North Sea; K, Kattegat). In marginal cases, we also provide the $\mathrm{p}$-values of the additive terms. Small p-values indicate the significance of the corresponding terms; however, these $p$-values are computed based on heuristics and should thus be interpreted with caution (NAO, North Atlantic Oscillation)

\begin{tabular}{|c|c|c|c|c|c|c|c|c|}
\hline & Lag 1 & $\begin{array}{l}\text { Transport } \\
\text { from S }\end{array}$ & $\begin{array}{l}\text { Transport } \\
\text { from N }\end{array}$ & $\begin{array}{l}\text { Transport } \\
\text { from K }\end{array}$ & Temperature & NAO & Outlier & $\begin{array}{c}\text { Adjusted } \\
\mathrm{R}^{2}(\%)\end{array}$ \\
\hline \multicolumn{9}{|c|}{ North Sea } \\
\hline Age 1 & & & & & & & & 15.0 \\
\hline Age 2 & Decreasing & & & & & & & 33.9 \\
\hline Age 3 & Decreasing & & & & Decreasing & Nonlinear & Y1973 & 73.0 \\
\hline Age 4 & Decreasing & & & Increasing & & & Y1973 & 69.9 \\
\hline Age 5 & Decreasing & & & & & & Y1981 & 82.0 \\
\hline Age 6 & Decreasing & & & $\begin{array}{c}\text { Decreasing } \\
\text { then increasing }\end{array}$ & & & & 87.7 \\
\hline \multicolumn{9}{|c|}{ Skagerrak } \\
\hline Age 1 & & & & & $\begin{array}{c}\text { Increasing } \\
\text { then decreasing }\end{array}$ & & & 31.8 \\
\hline Age 2 & Decreasing & & & Increasing & Decreasing & & & 60.2 \\
\hline Age 3 & & & Increasing & & $\begin{array}{c}\text { Decreasing } \\
\text { then increasing }\end{array}$ & & & 45.6 \\
\hline Age 4 & $\begin{array}{l}\text { Nonlinear, } \\
\text { decreasing }\end{array}$ & & & Increasing & $\begin{array}{c}\text { Decreasing } \\
\text { then } \\
\text { increasing }\end{array}$ & $\begin{array}{c}\text { Decreasing } \\
\text { then } \\
\text { increasing }\end{array}$ & Y1981 & 82.1 \\
\hline Age 5 & & & Increasing & & $\begin{array}{c}\text { Decreasing } \\
\text { then increasing } \\
(\mathrm{p}=0.052)\end{array}$ & & & 26.7 \\
\hline Age 6 & & & & & & Nonlinear & Y1981 & 48.5 \\
\hline \multicolumn{9}{|c|}{ Kattegat } \\
\hline Age 1 & & & & & & & & NA \\
\hline Age 2 & Decreasing & & & & & & & 49.6 \\
\hline Age 3 & $\begin{array}{r}\text { Decreasing } \\
\text { an }\end{array}$ & $\begin{array}{l}\text { Increase from } \\
\text { one level to } \\
\text { lother }(p=0.0\end{array}$ & & & & & & 56.9 \\
\hline Age 4 & $\begin{array}{l}\text { Decreasing } \\
\text { then increasing }\end{array}$ & & & & & & Y1981 & 82.1 \\
\hline Age 5 & Decreasing & $\begin{array}{l}\text { Nonlinear } \\
\text { with a maximu }\end{array}$ & & & & Nonlinear & Y1981 & 69.7 \\
\hline Age 6 & & & & & & Nonlinear & Y1981 & 34.6 \\
\hline
\end{tabular}




\section{A. Significant effects in North Sea region}
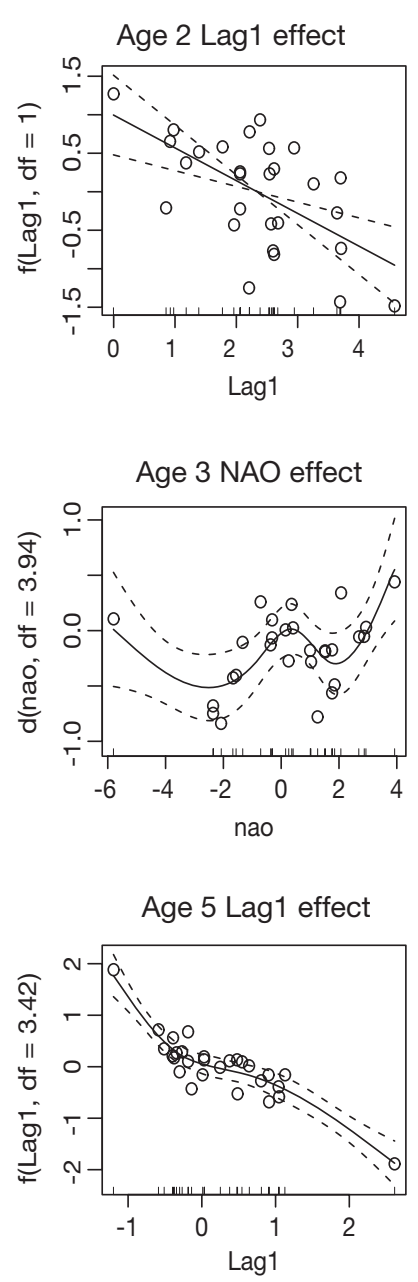
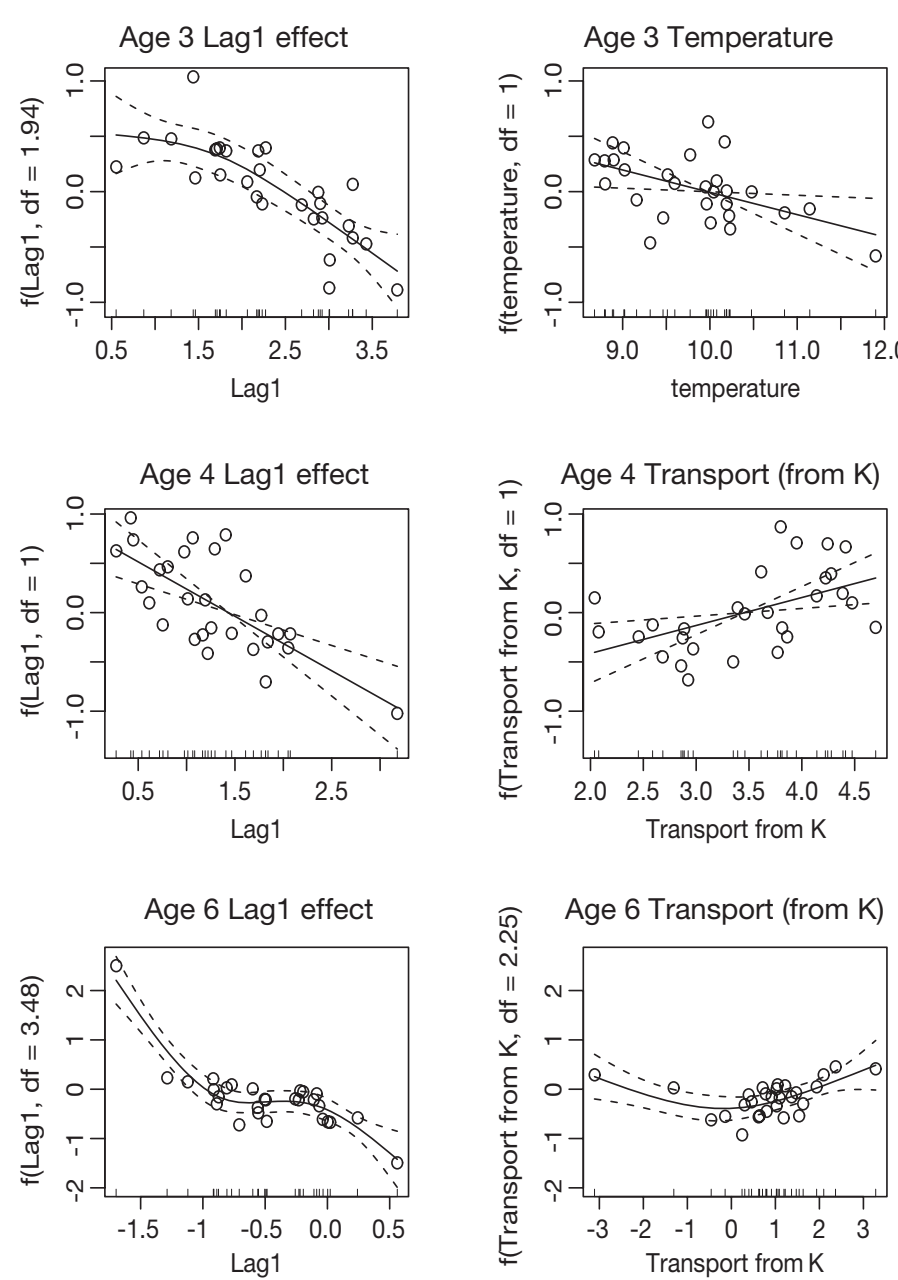
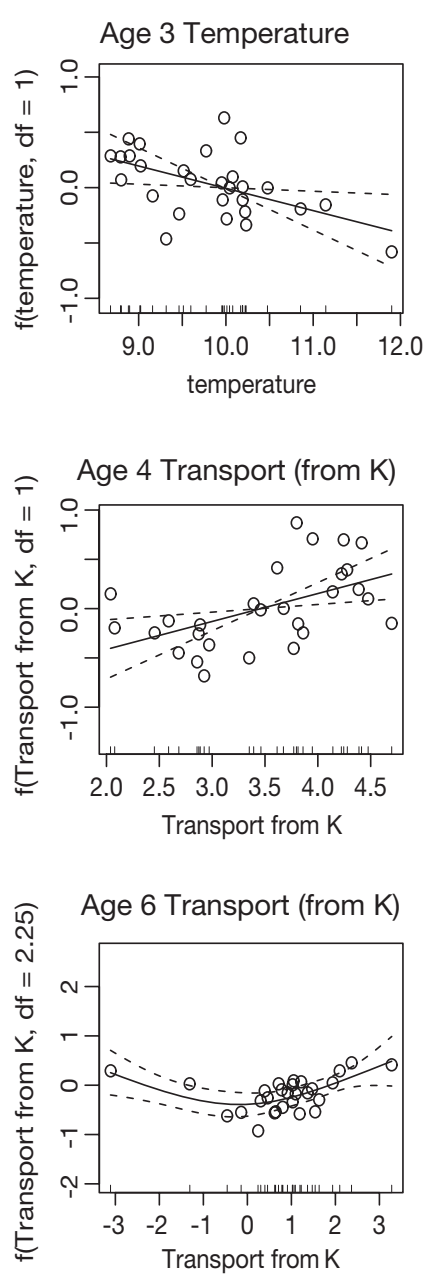

Fig. 3. (This and following 2 pages). Function estimates from the model with North Atlantic Oscillation (NAO) included as a covariate. Only significant function estimates are plotted. Significant effect shown in (A) North Sea region (N), (B) Skagerrak region (S), and (C) Kattegat region (K). Across the row(s) of panels, we plot the covariates (X-axis) versus the partial residuals (i.e. the corresponding response corrected for the additive effects from the covariates other than the one on the $x$-axis); the data points are drawn as open circles with the additive function estimates (solid lines) superimposed on the panels. In each panel, the title indicates the effect to be displayed, the $x$-label is the name of the covariate, say $x$, and the $y$-label is its corresponding additive effect with the estimated degree of freedom, denoted by $f(x, \mathrm{df}$ [= estimated degrees of freedom]). For example, the title of the first panel in the North Sea system indicates that it displays the Lag 1 effect on the Age Group 2. The $y$-label 'f(Lag 1, df = 1)' specifies that the estimated additive effect of Lag 1 has 1 degree of freedom, i.e. a linear effect. The dashed lines represent $95 \%$ confidence intervals. For those cases with the response variable being the log-abundance, the label is bold-faced. Otherwise, the response variable is the survival rate

Sea and Kattegat for this age group. For Age Groups 2 to $6+$, the Lag 1 effect (i.e. the density dependence) is significant, with a decreasing effect for most age groups in the 3 regions except Age Groups 3, 5 and 6+ in the Skagerrak and Age Group 6+ in the Kattegat. For these cases, the response variable is log-abundance, whereas the response variable is survival rate for all other cases. Temperature effect is found to be significant, decreasing for Age Group 2 and non-linear for Age Groups 1, 3, 4 and 5, in the Skagerrak, and significant, decreasing for Age Group 3, in the North Sea. The NAO has a significant non-linear effect on Age Group 3 in the North Sea, Age Groups 4 and 6+ in the Skagerrak and Age Groups 5 and $6+$ in the Kattegat.

A positive effect of mature cod migrating from the North Sea is observed for the Age Groups 3 and 5 in the Skagerrak. Similarly, a non-linear effect of migration from the Skagerrak is found for the Age Groups 3 and 5 in the Kattegat, while migration from the Kattegat increases in Age Groups 2 and 4 in the Skagerrak 


\section{B. Significant effects in Skagerrak region}
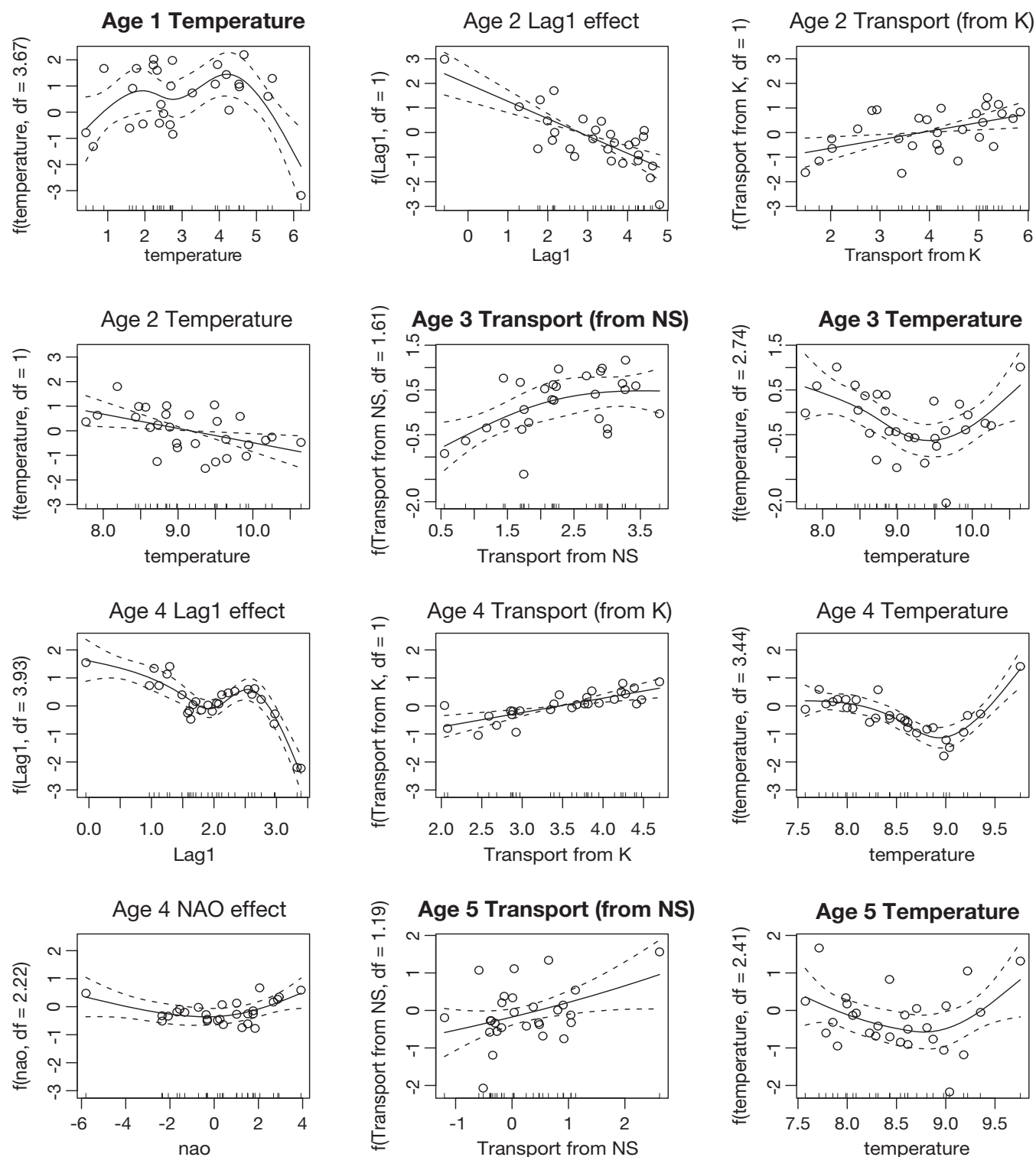

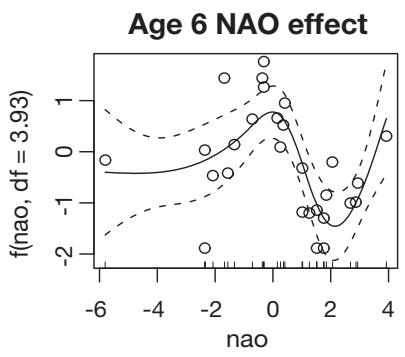

and Age Groups 4 and 6+ in the North Sea. The structure of the identified significant effects is schematically displayed in Fig. 4.

We have carried out model diagnostics by checking whether or not the errors satisfy the iid (i.e. indepen- dent and identical distribution) assumption. The autocorrelation plot of the residuals showed no significant autocorrelations for any age groups in the 3 regions. Also the errors appeared to be normally distributed for most cases. The residual versus fitted plots for the residuals appear to be random. Using the ccf function in the ts library of $\mathrm{R}$ we computed the cross-correlations of the residual time series. The results justified the assumption that the errors are contemporaneously and serially uncorrelated.

The model defined by Eqs. (4) to (9) considers the simple case of density-dependent effects occurring only in adjacent age groups. This has the potential 


\section{Significant effects in Kattegat region}
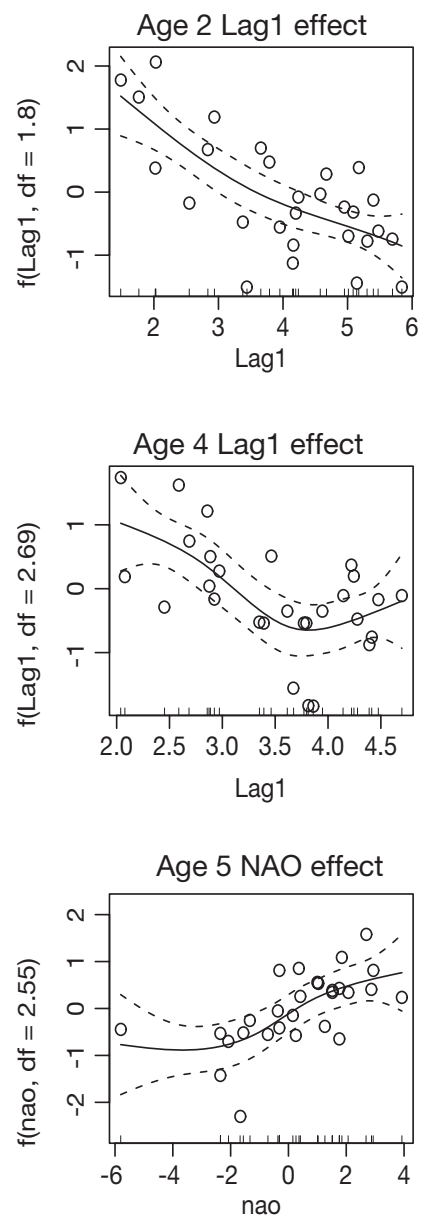
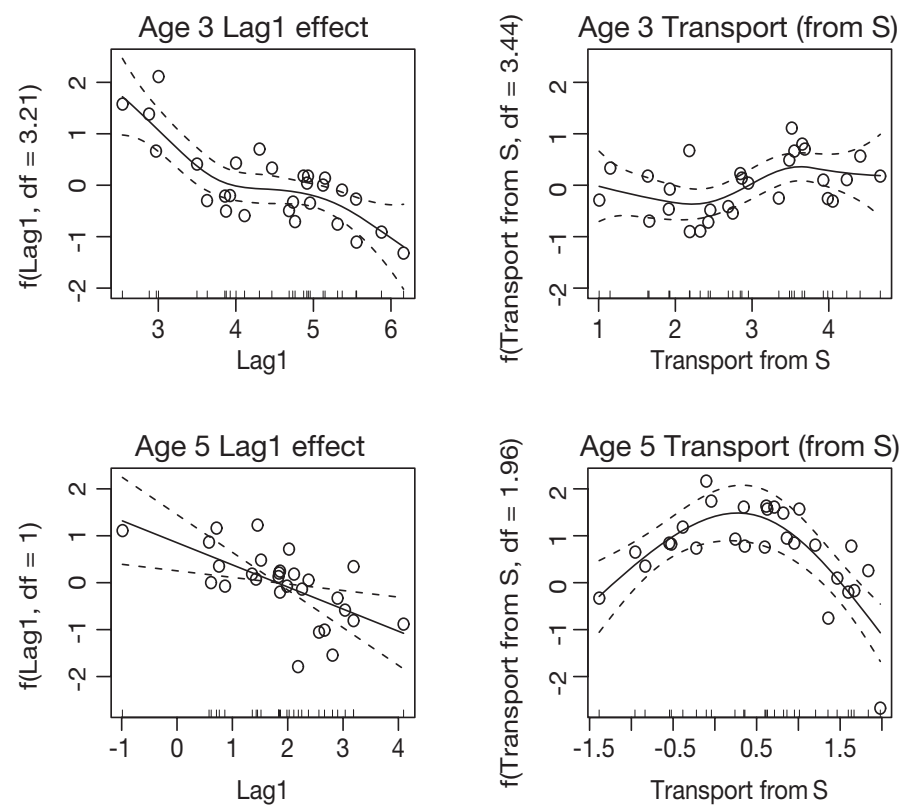

drawback of missing the role of cannibalism of big cod on small cod when abundance is highest, which is known to occur in cod stocks. To check this problem, we have also fitted models that include Lag 1 of the log-abundance of higher age groups in the model (with Lag 2 of Age Group 6+ as the covariate for the case of modeling Age Group 6+); all estimated cannibalism effects were found to be insignificant except for Age Group 4 in the Skagerrak and Kattegat, Age Group 5 in the Kattegat and Age Group 6+ in the North Sea. But the corresponding curve estimates of these 4 groups did not show a consistent pattern, thereby suggesting that the cannibalism effects found might well be spurious. Thus, we conclude that there is little empirical evidence of significant cannibalism effects beyond the adjacent age groups in the data.

A major assumption of the GAM is that the covariates affect the responses additively (Hastie \& Tibshirani 1990). This is a strong assumption that requires checking. The test of additivity (Chan et al. 2003) yielded non-significant results for most of the age groups in the 3 regions, except for 4 marginally significant test results ( $\mathrm{p}$-values between 0.025 and 0.045 ) out of 22 tests. Specifically, the tests for non-additivity suggest that for Age Group 3 in the North Sea, Lag 1 of North Sea cod abundance may interact with the sea temperature of the North Sea; in addition, there may be interaction between Lag 1 of North Sea cod abundance and NAO; for Age Group 5 in the Kattegat, the abundance of Lag 1 of Skagerrak cod may interact with NAO; for Age Group 6+ in the North Sea, Lag 1 of North Sea cod abundance may interact with that of the Kattegat. Our limited experience with the test, as well as simulations (over-rejection of about $15 \%$ for a sample size of 28 at the $5 \%$ significance level; not shown) suggest that the test for additivity tends to be anticonservative for data of small sample size. Given this and the fact that there is no consistency in the interaction patterns found, we thus find the assumption of additivity to be valid and obtained it for all age groups in all the areas. 


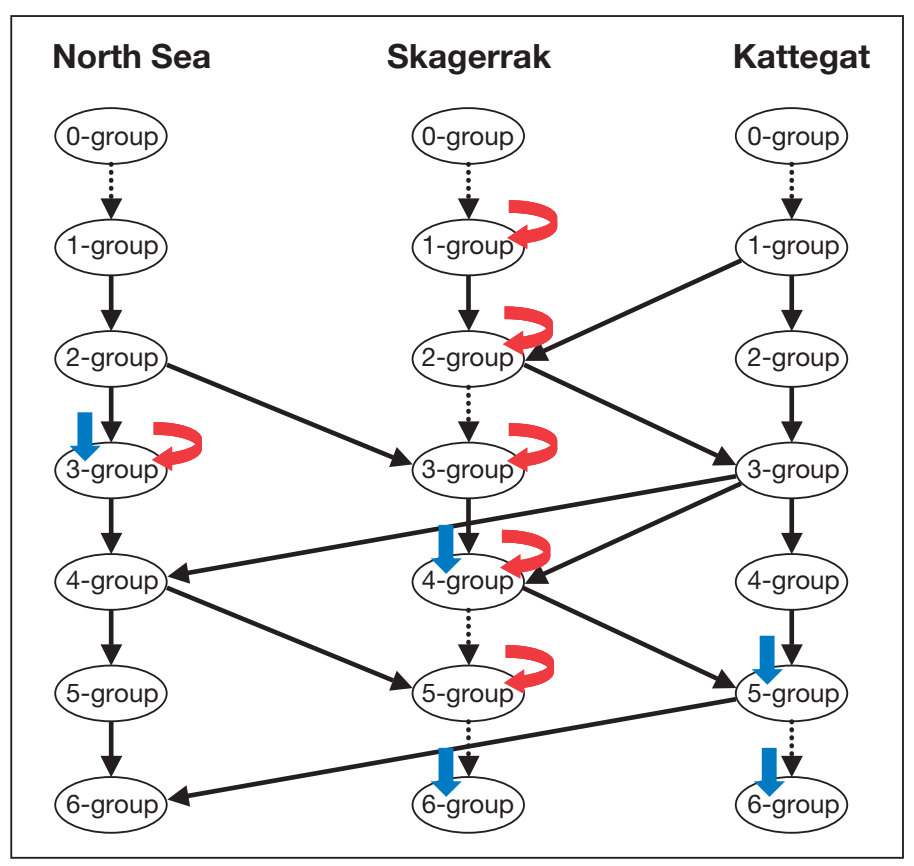

Fig. 4. Diagram of the significant effects found in the joint model (solid black lines, significant density dependence effects and transportation effects; dotted lines, insignificant density dependence; blue arrows, significant NAO effects; red circular arrows, significant temperature effects)

Altogether the estimated models were found to perform well-as judged from a statistical point of view (cf. the adjusted $\mathrm{R}^{2}$ in Table 2 ). We are also convinced that the deduced models capture several key features of the system: the cod stocks of the area are satisfactorily modeled with a density-dependent structure, incorporating effects of climate and interchange of individuals between the stocks. There is furthermore a connection between the stocks in the investigated area, in particular the Skagerrak area stock seem to be a recipient of immigrants from stocks in the other areas.

\section{DISCUSSION}

Our analysis has identified an interesting densitydependent structure in this cod system. The density dependence is significant in most cases for Age Groups 2 and above in all areas, and the functions are all very similar. We do believe these results represent real density dependencies since our data are survey data and not VPA-based values (see, e.g., Ulltang 1977), the latter of which might introduce spurious density dependence due to intrinsic density dependencies implicit in the VPA calculations. As such, our study provides a clear case of profound density dependence in marine fish populations.
We have demonstrated net migration effects (of mature individuals) from the North Sea to the Skagerrak, from the Kattegat to the Skagerrak and from the Kattegat to the North Sea. Such effects were demonstrated for 8 out of 32 possible relationships $(\mathrm{p}$-value $=0.00002$, computed based on the binomial distribution assuming that all 32 tests were independent). Tagging studies of cod in the North Sea have earlier suggested that many tagged individuals have traveled long distances and have a large geographic range (Gulland \& Williamson 1962), although the cod population is made up of several discrete stocks (Bedford 1966). Also Turner et al. (2002), using data storage tags, described migration and behavioral patterns over a year in the North Sea. Spawning migration is described in several papers (see, e.g., Garrod 1977, Daan 1978)

We were not able to demonstrate any direct effect of transportation of spawning products (Eqs. 5 \& 8). Earlier studies (Danielssen 1969, Pihl \& Ulmestrand 1993) have reported negligible migration across deep Norwegian waters, implying that there might be little contact between the Norwegian side of the Skagerrak and the North Sea, while there seems to be more migration between the Swedish and Danish parts of the Skagerrak and the North Sea. In general this is consistent with our findings. These results are also in agreement with observations based upon tagging experiments (Løversen 1946, Danielssen 1969, D. S. Danielssen \& J. Gjøsæter unpubl. data).

The model structure assumes that migration from one area to another is density-dependent (i.e. cod move to another area according to the density that they reach in the area where they are first found). However, movement can also be in relation to currents, and that may be particularly true for Age 1 cod. Indeed, there are indications both from plankton sampling and from genetic studies that North Sea cod larvae may be transported from spawning grounds in the North Sea into the Skagerrak, where they mix with natively produced larvae (Munk et al. 1995, 1999, Knutsen et al. 2004, Stenseth et al. unpubl. data). Such transportation may be mediated through favorable sea current and other environmental conditions such as water temperature (Cardinale \& Svedäng 2004, Knutsen et al. 2004, N. C. Stenseth et al. unpubl. data). The present data are, however, too rough for a detailed analysis of any effects of transport of the eggs and larvae. Yet this would be an interesting and worthwhile research problem in the future.

There are well-established cases of migration of cod between different management units, even over rela- 
tively large distances. The classic example is cod spawned at Iceland drifting to Greenland as eggs and larvae (Tåning 1937, Buch et al. 1994, Schopka 1994). This transport is a regular occurrence. The fate of the juvenile cod later on varies; survival at Greenland has been very low during the last 15 to 20 yr (ICES 2002b). However, when environmental conditions are suitable off West Greenland, these cod may thrive and subsequently return to Iceland to spawn (Dickson \& Brander 1993, Schopka 1994, ICES 2002b). This return migration, estimated at 50 million fish per year during the $1970 \mathrm{~s}$, each weighing around $2.5 \mathrm{~kg}$, can result in large uncertainties in the assessment of the Icelandic stock (Shepherd \& Pope 1993, ICES 2002b). The return of the 1945 year class alone represented an unpredicted increment of over 700000 tonnes of $8 \mathrm{yr}$ old cod in Iceland (Schopka 1991, Dickson \& Brander 1993).

Temperature has a distinct effect on many of the age classes. Much as expected (e.g. Pepin 1991), temperature may affect the population dynamics of fish populations. However, the regional differences are pronounced: none of the age classes in the Kattegat area and only 1 of the age classes of the North Sea (Age 2) is affected by temperature, while all age classes except for the $6+$ age class are affected in the Skagerrak (Table 2, Fig. 3). These regional differences are difficult to explain. The monthly sea temperature distribution of the Skagerrak is similar to that of the Kattegat, but the former appears to be more symmetric. That of the North Sea is relatively higher and more variable than that of the other 2 regions, see Fig. 5. Earlier authors have suggested that stocks towards the higher end of the overall temperature range for cod, like the regions studied here, would benefit from temperatures below the average (Planque \& Frédou 1999). However, our study is different in that we also examined for nonlinear effects. The regional differences in the climate-cod linkage may, to a certain degree, be due to the Skagerrak being more homogenous temperaturewise than the other 2 regions. The North Sea is relatively large, with pronounced higher temperatures in the south than in the north, while some parts of the Kattegat are more influenced by colder water masses of Baltic origin than others.

Earlier a pattern of increasing ambient winter temperature with age was observed in the North Sea. For instance in February, 1 yr old cod were, as a rule, found in the coldest water, 2 yr old cod were at highest densities at somewhat higher temperatures, and older fish occurred at the upper end of the temperature range (Daan et al. 1994). However, this North Sea cod pattern shifts markedly with the season. In autumn, 0- and 1group cod live at higher ambient temperatures than the average North Sea values, whereas the opposite is the case for the oldest age groups. Daan et al. (1994)
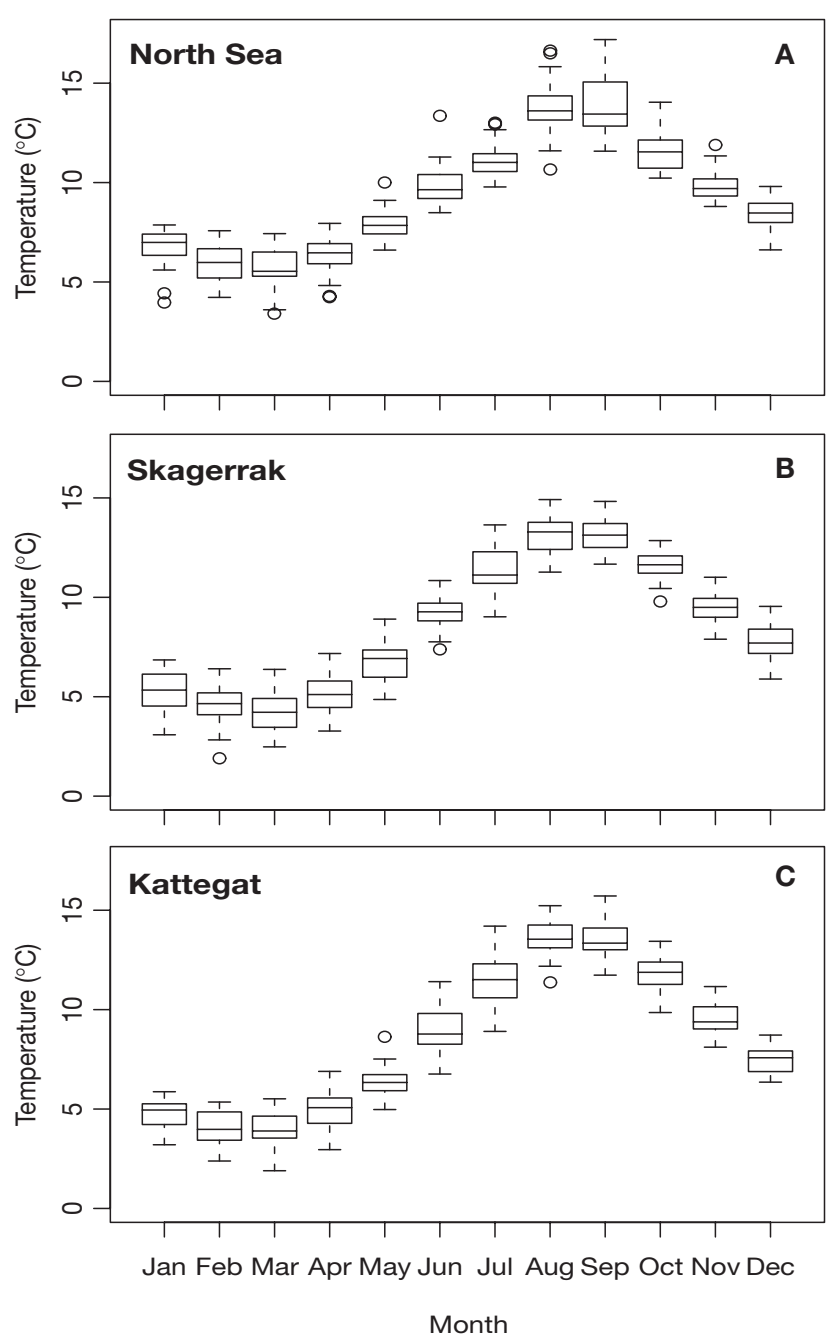

Fig. 5. Monthly distribution of sea temperature averaged over the period 1970 to 2001 (obtained from the ICES oceanographic database; www.ices.dk/ocean) for (A) the North Sea, (B) Skagerrak and (C) Kattegat. Monthly means are represented by a line within each box. Each box spans the middle $50 \%$ temperature data, with the whiskers extending to the minimum and maximum monthly temperatures

argued that these differences in temperature distribution between age groups in the North Sea reflected geographic differences in distribution rather than specific temperature preferences, at least for juveniles. Older cod appear to buffer themselves against temperature fluctuations by occupying areas of the North Sea where the seasonal fluctuation in temperature is minimal, whereas juvenile cod occupy areas of the North Sea where seasonal variation in temperature is large and are thus exposed to the lowest winter temperatures and the highest summer temperatures (Daan et al. 1994). Furthermore, Myers \& Stokes (1989) observed that North Sea cod of Age 1 responded to an overall increase in population density with a relatively 
greater increase in the prime habitat, i.e. increased population density led to higher concentration. However, North Sea cod show no systematic pattern of change in spatial distribution to compensate for interannual temperature variability (Daan et al. 1994). A shift in the average North Sea winter bottom temperature results in an about equally large shift in the ambient temperature of cod.

The effects of NAO are only seen for the oldest age group and for 3 other age groups (Table 2, Fig. 3). We thus suggest that the effect of the NAO is weak. It is interesting, however, to observe that when the NAO does have an effect, it generally tends to be highly non-linear, with a positive peak right around 0 , and a drop on either side. We are unsure of why this is so.

If the 3 areas considered here are connected (e.g. by transportation of spawning products), we might expect the dynamics of the populations to be similar. Indeed, this is the case as shown by the within- and between-region contemporaneous correlations between the various age groups; see Table 3. For example, out of the 15 pairs of distinct within-region correlation coefficients for the North Sea cod, 4 pairs are significant, whereas the expected number of false positives is equal to 0.75 . (The probability of observing 4 or more false positives is 0.00061 , assuming a binomial [ $\mathrm{n}=15, \mathrm{p}=0.05]$ distribution for the number of false positives.) Similarly, there are 8 and 5 significant within-region correlations for the Skagerrak and the Kattegat, respectively. Interestingly, there are 7 significant correlations between the North Sea and the Skagerrak, and the same number of significant correlations between the Skagerrak and Kattegat, but none of the correlations between the North Sea and Kattegat are significant. Also, the significant correlations between the North Sea and Skagerrak are mainly either on or below the diagonal, suggesting migration of some Skagerrak cod to the North Sea. Similarly, there is some evidence that the Skagerrak cod abundance led the Kattegat cod abundance, suggesting migration of some Skagerrak cod to the Kattegat.

While Koslow (1984) and Koslow \& Thompson (1987) showed correlation/synchrony in recruitment in the northwestern Atlantic cod stocks, Myers et al. (1995a,b, 1997) suggested that there is generally not a great deal of correlation/synchrony among cod stocks at great distances; the limit seems to be around $500 \mathrm{~km}$. In summary, these all support the position that there is some synchrony among several Atlantic stocks being separated by $<500 \mathrm{~km}$.

There are, however, several possible mechanisms that can act to synchronize the populations. Environ-

Table 3. Contemporaneous correlations between and within region of the Age Groups 1 to $6+$ ( $\mathrm{S}$, Skagerrak; $\mathrm{K}$, Kattegat; $\mathrm{N}$, North Sea). Correlations are coded as follows: ' - ' $={ }^{\prime} 0-0.38$ ', ' $\mathrm{A}^{\prime}={ }^{\prime} 0.38-0.6$ ', ' $\mathrm{B}$ ' = '0.6-0.8', ' $\mathrm{C}^{\prime}={ }^{\prime} 0.8-0.95$ ' and ${ }^{\circ} \mathrm{D}$ ' $={ }^{\prime} 0.95-1.0$ '. Blue symbols stand for positive correlations, and red symbols for negative correlations. Correlations of 0.38 and above are significant at the $5 \%$ significance level

\begin{tabular}{|lllllll|lllllll|}
\hline Age & 1 & 2 & 3 & 4 & 5 & 6 & Age & 1 & 2 & 3 & 4 & 5 & 6 \\
\hline $\mathbf{N} \mathbf{N}$ & & & & & & & NIS & & & & & & \\
1 & D & & & & & & 1 & - & - & - & - & - & - \\
2 & - & D & & & & & 2 & - & A & - & - & - & - \\
3 & - & - & D & & & & 3 & - & - & A & A & - & - \\
4 & - & - & - & D & & & 4 & - & - & - & A & - & - \\
5 & - & - & A & - & D & & 5 & - & - & A & - & - & - \\
6 & - & - & A & B & A & D & 6 & - & - & A & A & - & - \\
\hline SIS & & & & & & & NIK & & & & & & \\
1 & D & & & & & & 1 & - & - & - & - & - & - \\
2 & - & D & & & & & 2 & - & - & - & - & - & - \\
3 & - & A & D & & & & 3 & - & - & - & - & - & - \\
4 & - & A & A & D & & & 4 & - & - & - & - & - & - \\
5 & - & - & A & A & D & & 5 & - & - & - & - & - & - \\
6 & - & A & A & A & - & D & 6 & - & - & - & - & - & - \\
\hline KIK & & & & & & & SIK & & & & & & \\
1 & D & & & & & & 1 & - & A & - & - & - & - \\
2 & - & D & & & & & 2 & - & A & - & A & - & - \\
3 & - & - & D & & & & 3 & - & - & A & - & - & A \\
4 & - & A & - & D & & & 4 & - & - & - & A & - & - \\
5 & - & - & A & - & D & & 5 & - & - & - & - & - & - \\
6 & - & - & A & A & A & D & 6 & - & - & - & - & - & A \\
\hline
\end{tabular}


mental forcing, such as temperature, may synchronize population fluctuations in space. This is the so-called Moran effect, which has received much attention (Ranta et al. 1997, 1999, Stenseth et al. 2002). However, neither temperature nor the NAO is displayed as such a factor in our results - only the Skagerrak data are systematically influenced by temperature (for all age groups except for the $6+$ group).

A more direct, environmental forcing factor may be the large-scale circulation in the Skagerrak and Kattegat basins (Danielssen et al. 1997) (see 'Introduction'). This circulation has been demonstrated to influence genetic structure of cod populations along the Norwegian Skagerrak coast (Knutsen et al. 2004) and, indirectly, to influence species richness in the same area (Lekve et al. 2002, 2003) and along the Swedish Skagerrak coast (Svedäng 2003).

Altogether we have been able to quantify feedback interactions between various age components of cod within any given stock as well as between stocks. Specifically, our analysis shows: (1) A remarkable similarity in the population dynamic equations is found between the North Sea, Skagerrak and Kattegat-a result which strengthens the validity of the deduced model structure. (2) Clear statistical effects of density dependence both within and between age classes are found $-\mathrm{a}$ result of quite general interest since the presence of density dependence in marine systems is not generally appreciated (but see Bjørnstad et al. 1999a,b, Stenseth et al. 1999). (3) Clear statistical effects of what seems to be the results of migrations of mature individuals are found - a conclusion with clear management implications (see below).

We cannot, however, draw any conclusions about the transport of spawning products (eggs or larvae) - the data are simply too rough for such an analysis. On the other hand, we have also found a clear effect of climate - an effect which is largely consistent with previous results (see several papers in Daan et al. 1994). Altogether our results strongly suggest a unified management regime for the oceanic cod stocks in the North Sea and surrounding areas (Skagerrak and Kattegat) - but one within which the subdivision of the different stocks is taken into consideration in management procedures. This would contribute to the conservation of the cod in this region (see also Frank \& Brickman 2000).

Acknowledgements. The ICES Secretariat, Copenhagen, is thanked for allowing us access to the ICES International Bottom Trawl Survey database. These studies have partly been supported by the Nordic Council of Ministers, the Norwegian Research Council and the University of Oslo. Comments on an earlier draft of this paper by Lorenzo Ciannelli are greatly appreciated.

\section{LITERATURE CITED}

Anon. (2004) Report of the International Bottom Trawl Survey Working Group ICES Resources Management Committee. ICES CM 2004/D:05. Available at www.ices.dk/reports/ RMC/2004/IBTSWG/ibtswg04.pdf

Bedford BC (1966) English cod tagging experiments in the North Sea. ICES CM 1966(G9):1-28

Bjørnstad ON, Fromentin JM, Stenseth NC, Gjøsæter J (1999a) Cycles and trends in cod populations. Proc Natl Acad Sci USA 96:5066-5071

Bjørnstad ON, Fromentin JM, Stenseth NC, Gjøsæter J (1999b) A new test for density-dependent survival: the case of coastal cod populations. Ecology 80:1278-1288

Brander KM (1994) The location and timing of cod spawning around the British Isles. ICES J Mar Sci 51:71-89

Buch E, Horsted SA, Hovgård H (1994) Fluctuations in the occurrence of cod in the Greenland waters and their possible causes. ICES Mar Sci Symp 198:158-174

Cardinale M, Svedäng H (2004) Modelling recruitment and abundance of Atlantic cod, Gadus morhua, in the eastern Skagerrak-Kattegat (North Sea): evidence of severe depletion due to a prolonged period of high fishing pressure. Fish Res Amst 69:263-282

Chan KS, Kristoffersen AB, Stenseth NC (2003) Bürmann expansion and test for addititvity. Biometrika 90:209-222

Daan N (1978) Changes in cod stocks and cod fisheries in the North Sea. Rapp PV Reun Cons Int Explor Mer 172:39-57

Daan N, Heessen HJL, Pope JG (1994) Changes in the North Sea cod stock during the twentieth century. ICES Mar Sci Symp 198:229-243

Danielssen DS (1969) On the migration of cod in the Skagerrak shown by tagging experiments in the period 1954-1965. Fiskeridir Skr Ser Havunders 15:331-338

Danielssen DS, Gjøsæter J (1994) Release of 0-group cod, Gadus morhua L., on the southern coast of Norway in the years 1986-1989. Aquacult Fish Manag 25:129-142

Danielssen DS, Svendsen E, Ostrowski M (1996) Long-term hydrographic variation in the Skagerrak based on the section Torungen-Hirtshals. ICES J Mar Sci 53:917-925

Danielssen DS, Edler L, Fonselius S, Hernroth L, Ostrowski M, Svendsen E, Talpsepp L (1997) Oceanographic variability in the Skagerrak and northern Kattegat, May-June, 1990. ICES J Mar Sci 54:753-773

Danke L (1967) Erster Bericht über Kabeljaumarkierung 1964 bis 1966 bei Labrador. Fischereiforschung 5:87-91

Dickson RR, Brander KM (1993) Effects of a changing windfield on cod stocks of the North Atlantic. Fish Oceanogr 2: 124-153

Frank KT, Brickman D (2000) Allee effects and compensatory population dynamics within a stock complex. Can J Fish Aquat Sci 57:513-517

Garrod DJ (1977) The North Atlantic cod. In: Gulland JA (ed) Fish population dynamics. John Wiley \& Sons, London, p 216-242

Gulland JA, Williamson GR (1962) Transatlantic journey of a tagged cod. Nature 195(4844):921

Hastie TJ, Tibshirani RJ (1990) Generalized additive models. Chapman \& Hall, London

Hovgård H, Christensen S (1990) Population structure and migration patterns of Atlantic cod (Gadus morhua) in West Greenland waters based on tagging experiments from 1946-1964. NAFO (Northwest Atl Fish Organ) Sci Counc Stud 14:45-50

Howarth MJ (2001) North Sea circulation. In: Steele JH, Turekian KK, Thorpe SA (eds) Encyclopedia of ocean sciences, Vol 4. Academic Press, London, p 1912-1921 
Hurrell JW (1995) Decadal trends in the North Atlantic Oscillation: regional temperatures and precipitation. Science 269:676-679

ICES (International Council for the Exploration of the Sea) (1994) Spawning and life history information for North Atlantic cod stocks. ICES Coop Res Rep 205:150

ICES (2001) Report of the Working Group on the Assessment of Demersal Stocks in the North Sea and Skagerrak, October 2000. ICES CM 2001/ACFM:7

ICES (2002a) Report of the Working Group on the Assessment of Demersal Stocks in the North Sea and Skagerrak. ICES CM 2002/ACFM:01:565

ICES (2002b) Workshop on the transport of cod larvae. ICES CM C:13:45

Knutsen H, Jorde PE, Andre C, Stenseth NC (2003) Finescaled geographical population structuring in a highly mobile marine species: the Atlantic cod. Mol Ecol 12:385-394

Knutsen $\mathrm{H}$, André C, Jorde, PE, Skogen DM, Thuróczy E, Stenseth NC (2004) Transport of North Sea cod larvae into the Skagerrak coastal populations. Proc R Soc Lond B 271: 1337-1344

Koslow A (1984) Recruitment patterns in Northwest Atlantic fish stocks. Can J Fish Aquat Sci 41:1722-1729

Koslow JA, Thompson KR (1987) Recruitment to Northwest Atlantic cod (Gadus morhua) and haddock (Melanogrammus aeglefinus) stocks: influence of stock size and climate. Can J Fish Aquat Sci 44:26-39

Kurlansky M (1997) Cod: a biography of the fish that changed the world. Jonathan Cape, London

Lekve K, Boulinier T, Stenseth NC, Gjøsæter J, Fromentin JM, Hines JE, Nichols JD (2002) Spatio-temporal dynamics of species richness in coastal fish communities. Proc R Soc Lond B 269:1781-1789

Lekve K, Stenseth NC, Johansen R, Lingjærde OC, Gjøsæter J (2003) Richness-dependent and climatic factors regulating the dynamics of coastal fish diversity. Ecol Lett 6: $428-439$

Løversen R (1946) Torskens vekst og vandring på Sørlandet. Fiskeridir Skr Ser Havunders 8:1-27

Munk P, Larsson PO, Danielssen DS, Moksness E (1995) Larval and small juvenile cod Gadus morhua concentrated in the highly productive areas of a shelf break front. Mar Ecol Prog Ser 125:21-30

Munk P, Larsson PO, Danielssen DS, Moksness E (1999) Variability in frontal zone formation and distribution of gadoid fish larvae at the shelf break in the northeastern North Sea. Mar Ecol Prog Ser 177:221-233

Myers RA, Mertz G, Barrowman NJ (1995a) Spatial scales of variability in cod recruitment in the North Atlantic. Can J Fish Aquat Sci 52(9):1849-1862

Myers RA, Barrowman NJ, Thompson KR (1995b) Synchrony of recruitment across the North Atlantic: an update. (Or, 'now you see it now you don't!'). ICES J Mar Sci 52:103-110

Myers RA, Mertz G, Bridson J (1997) Spatial scales of interannual recruitment variations of marine, anadromous, and freshwater fish. Can J Fish Aquat Sci 54:1400-1407

Nielsen EE, Hansen MM, Schmidt C, Meldrup D, Grønkjær P (2001) Determining the population of origin of individual cod in the Northeast Atlantic. Nature 413:272

Nielsen E, Hansen MM, Ruzzante DE, Meldrup D, Grønkjær P (2003) Evidence of a hybrid-zone in Atlantic cod (Gadus morhua) in the Baltic and the Danish Belt Sea revealed by individual admixture analysis. Mol Ecol 12:1497-1508

Ottersen G, Søiland H, Svendsen E, Danielssen D (2003) Temporal and spatial hydrographic variability in the Skagerrak evaluated by observations and model results. Fisken Havet 2:1-32
Pepin P (1991) Effect of temperature and size on development, mortality, and survival rates of the pelagic early life history stages of marine fish. Can J Fish Aquat Sci 48: 503-518

Pihl L, Ulmestrand M (1993) Migration pattern of juvenile cod (Gadus morhua) on the Swedish West-Coast. ICES J Mar Sci 50:63-70

Planque B, Frédou T (1999) Temperature and the recruitment of Atlantic cod (Gadus morhua). Can J Fish Aquat Sci 56: 2069-2077

Ranta E, Kaitala V, Lindstrom J, Helle E (1997) The Moran effect and synchrony in population dynamics. Oikos 78 : 136-142

Ranta E, Kaitala V, Lindstrom J (1999) Spatially autocorrelated disturbances and patterns in population synchrony. Proc R Soc Lond B 266:1851-1856

Riley JD, Parnell WG (1984) The distribution of young cod. In: Dahl E, Danielssen DS, Moksness E, Solemdal P (eds) The propagation of cod (Gadus morhua L.). Institute of Marine Research, Arendal, p 563-580

Røed LP, Fossum I (2004) Mean and eddy motion in the Skagerrak/northern North Sea: insight from a numerical model. Ocean Dyn 54:197-220

Schopka SA (1991) The Greenland cod at Iceland, 1941-1990 and its impact on assessment. NAFO Scr Doc 91/102:1-7

Schopka SA (1994) Fluctuations in the cod stock off Iceland during the twentieth century in the fisheries and environment. ICES Mar Sci Symp 198:175-193

Shepherd JG, Pope JG (1993) Alternative methods for the estimation of immigration to the Icelandic cod stock. Fish Oceanogr 2:3-4

Stenseth NC, Bjørnstad ON, Falck W, Fromentin JM, Gjøsæter J, Gray JS (1999) Dynamics of coastal cod populations: intra- and intercohort density dependence and stochastic processes. Proc R Soc Lond B 266:1645-1654

Stenseth NC, Mysterud A, Ottersen G, Hurrell JW, Chan KS, Lima M (2002) Ecological effects of climate fluctuations. Science 297:1292-1296

Stenseth NC, Ottersen G, Hurrell JW, Mysterud A, Lima M, Chan KS, Yoccoz NG, Adlandsvik B (2003) Studying climate effects on ecology through the use of climate indices: the North Atlantic Oscillation, El Niño Southern Oscillation and beyond. Proc R Soc Lond B 270:2087-2096

Stokes K, Myers RA (1989) Density-dependent habitat utilization of groundfish and the improvement of research surveys. ICES CM 1989/D:15

Svedäng H (2003) The inshore demersal fish community on the Swedish Skagerrak coast: regulation by recruitment from offshore sources. ICES J Mar Sci 60:23-31

Tåning AV (1937) Some features in the migration of cod. J Cons Perm Int Explor Mer 23:366-370

Turner K, Righton D, Metcalfe JD (2002) The dispersal patterns and behaviour of North Sea cod (Gadus morhua) studied using electronic data storage tags. Hydrobiologia 483:201-208

Ulltang $\varnothing$ (1977) Sources of errors in and limitations of virtual population analysis (cohort analysis). J Cons Int Explor Mer 37:249-260

Wood SN (2000) Modelling and smoothing parameter estimation with multiple quadratic penalties. J R Stat Ser B 62: 413-428

Wood SN (2001) mgcv: GAMs and generalized ridge regression for R. R News 1/2:20-25. Available at http://cran.rproject.org/doc/Rnews/

Wood SN (2004) Stable and efficient multiple smoothing parameter estimation for generalized additive models. J Am Stat Assoc 99:637-686 